\title{
Françoise Perus: la crítica materialista en la "crisis del tiempo"**
}

\author{
Françoise Perus: materialist criticism in the "crisis of time"
}

\begin{abstract}
Andrés Kozel ${ }^{* *}$
Resumen: El artículo aborda la obra de Françoise Perus, crítica literaria de origen francés radicada en América Latina desde hace más de medio siglo. Busca ofrecer respuestas a tres interrogantes: 1) cómo convendría periodizar y organizar su obra; 2) cuáles son sus principales aportes teóricos; 3) qué intersecciones cabe perfilar entre tales aportes y el estudio de elaboraciones textuales no ficcionales, como el ensayo de ideas. Los tres interrogantes se inscriben dentro de una pregunta más amplia relativa al procesamiento de la "crisis del tiempo" (Hartog) por parte de la intelectualidad latinoamericana contemporánea, en la convicción de que en la obra de Perus se encuentra una modulación singularmente lúcida y coherente de esa compleja experiencia.
\end{abstract}

Palabras clave: Françoise Perus, crisis del tiempo, forma artística, intelectualidad latinoamericana.

\begin{abstract}
This article deals with the work of Françoise Perus, French literary critic established in Latin America for more than half a century. It seeks to put forward answers to three questions: 1) how should we organize her work in periods; 2) what its main theoretical contributions are; 3) what intersections can be outlined between such contributions and the study of non-fictional textual elaborations, such as the "essay of ideas". These questions are situated as part of a broader one that pertains to the processing of the "time crisis" (Hartog) by the contemporary Latin American intellectuality. They also stem from the conviction that there is in Perus a singularly lucid and coherent modulation of that complex experience.
\end{abstract}

Key words: Françoise Perus, crisis of time, artistic form, Latin American intellectuality.

Recibido: 24 septiembre 2019 Aceptado:14 noviembre 2019

\footnotetext{
* Una versión preliminar fue presentada en el simposio "Protagonismos femeninos latinoamericanos en teoría, crítica y gestión cultural", coordinado por Marcela Croce y Jimena Néspolo dentro del IX Congreso Iberoamericano de Estudios de Género / XIV Jornadas Nacionales de Historia de las Mujeres (Mar del Plata, julio-agosto de 2019). El autor hace constar su agradecimiento a dicha instancia por haberlo motivado a emprender un ejercicio de sistematización sobre el legado de Françoise Perus.

** Argentino. Sociólogo por la Universidad de Buenos Aires (UBA) y doctor en Estudios Latinoamericanos por la Universidad Nacional Autónoma de México (UNAM). Investigador de carrera del Consejo Nacional de Investigaciones Científicas y Técnicas (CONICET) radicado en el Laboratorio de Investigación en Ciencias Humanas (LICH) de la Universidad Nacional de San Martín (UNSAM).
} 


\section{Propósito}

Françoise Perus (1936) es una crítica literaria de origen francés radicada en América Latina desde su juventud. A lo largo del último medio siglo ha realizado una relevante labor docente e investigativa, en particular en el marco de la Universidad Nacional Autónoma de México, país donde se estableció en 1973, tras haber residido en Ecuador y, por un breve periodo, en Chile. En 1981 Perus obtuvo el grado de Maestra en Letras Hispánicas por la Universidad Paul Valéry, de Montpellier. Sus libros principales son cinco. Se refieren al modernismo, al realismo social, a las poéticas narrativas de las novelas María y La vorágine, a la poética narrativa de Juan Rulfo, y a los modos por los cuales la crítica literaria ha considerado la cuestión de la forma artística en las últimas décadas. ${ }^{1}$ Perus también ha publicado numerosos artículos y capítulos de libros, destacando entre ellos sus estudios de las poéticas narrativas de las novelas Canaima y Al filo del agua, incluidos en los volúmenes correspondientes de la Colección Archivos. ${ }^{2}$ Si bien incidentalmente abordó obras de algunos clásicos decimonónicos como Sarmiento y Martí, el foco de su labor investigativa ha sido la literatura latinoamericana del siglo XX, especialmente la correspondiente a las fases previas al denominado boom. Interesa igualmente consignar que Perus ha organizado e introducido dos antologías de textos teóricos referidos a los vínculos entre historia y ficción. ${ }^{3}$

El presente estudio se propone ofrecer respuestas, por supuesto que provisionales, a tres interrogantes. El primero se refiere a cómo convendría periodizar y organizar la obra de Perus. El segundo concierne a establecer cuáles son los principales aportes teóricos que contiene. En este punto es de la mayor importancia tener presente que en la obra de Perus se verifica una relación intensa -reflexiva, crítica, creativa- con la "teoría". En efecto, leer a Perus es adentrarse en un vibrante contrapunteo con los puntos de vista de Georg Lukács, Lucien Goldmann, Louis Althusser, Yuri Lotman, Mijaíl Bajtín, Paul Ricœur, Edmond Cros (y otros representantes de la sociocrítica), Jacques Rancière; y, en América Latina, José Carlos Mariátegui, Emir Rodríguez Monegal, Ángel Rama, Antonio Cornejo Polar... Por lo demás, el caso de Perus es, según veremos, sumamente interesante desde el punto de vista del estudio de los procesos de recepción de enfoques y categorías no latinoamericanas en América Latina. El tercero tiene que ver con pensar qué intersecciones pueden perfilarse

\footnotetext{
${ }^{1}$ Perus, Françoise, Literatura y sociedad en América Latina: el modernismo, México, Siglo Veintiuno, 1978 [1 $1^{\mathrm{a}}$ ed. La Habana, 1976]; El realismo social en perspectiva. México, IIS-UNAM, 1995 [edición revisada con respecto a la $1^{\text {a }}$ de 1982: el título de la $1^{a}$ ed. es Historia y crítica literaria. El realismo social y la crisis de la dominación oligárquica]; De selvas y selváticos: ficción autobiográfica y poética narrativa en Jorge Issacs y José Eustasio Rivera, Bogotá, Universidad Nacional de Colombia / Universidad de los Andes / Plaza \& Janés, 1998; Juan Rulfo, el arte de narrar, México, UNAM, 2012; Transculturaciones en el aire. En torno a la cuestión de la forma artística en la crítica de la narrativa hispanoamericana, México, UNAM, 2019.

${ }^{2}$ Perus, Françoise, "Universalidad del regionalismo: Canaima de Rómulo Gallegos", en Rómulo Gallegos, Canaima, edición crítica coordinada por Charles Minguet, ALLCA XX, Colección Archivos, 1991; "La poética narrativa de Agustín Yáñez en Al filo del agua", en Agustín Yánez, Al filo del agua, edición crítica coordinada por Arturo Azuela, ALLCA XX, Colección Archivos, 1992. Varios otros artículos y capítulos de la autora son referidos a lo largo del estudio y en la bibliografía que lo cierra.

${ }^{3}$ Perus, Françoise (comp.), Historia y literatura, México, Instituto Mora, 2001 [1 $1^{\text {a }}$ ed. 1994], y La historia en la ficción y la ficción en la historia. Reflexiones en torno a la cultura y algunas nociones afines: historia, lenguaje y ficción, México, IIS-UNAM, 2009.
} 
entre los aportes de Perus y el estudio de elaboraciones textuales no ficcionales, como el ensayo de ideas.

Los tres interrogantes se inscriben dentro de una pregunta más amplia relativa al procesamiento de la "crisis del tiempo" por parte de la intelectualidad latinoamericana contemporánea. El caso de Perus expresa una modulación lúcida y coherente de esa compleja experiencia. Para pensar esta dinámica acudo a un dispositivo teórico integrado por herramientas de variada procedencia. En primer lugar, contribuciones realizadas por François Hartog en su obra sobre los regímenes de historicidad, donde la noción "crisis del tiempo" juega un papel. En segundo, cuestiones trabajadas por Carl Schorske en su libro clásico, en particular, la idea según la cual, durante fases críticas, se incorporan "héroes culturales" de nuevo talante. En tercero, aportes de Elías Palti, en especial, su modo de encarar las dinámicas de "crisis conceptual" y, sobre todo, su distinción entre deslizamientos ideológicos y cambios conceptuales. En cuarto, la noción de "microrrevolución semántica", introducida por Luciano Egido para pensar ajustes no estentóreos. En quinto, consideraciones vertidas por Eduardo Devés en relación con los procesos de agotamiento y sustitución de "marcos de referencia" (de acuerdo con Devés, tales procesos pueden implicar vivencias tortuosas y desgarramientos estremecedores; en la medida de ello, resultan de gran interés para los estudiosos de las ideas). ${ }^{4}$

Un punto importante que cabe adelantar, porque dota al presente análisis de cierta extraña y espejeante circularidad, es que el dispositivo analítico que empleo para analizar el caso de Perus debe bastante a enseñanzas de la propia Perus, quien se ocupó con especial esmero de la problemática de la temporalidad. La última consideración introductoria que corresponde realizar es que, más allá de algunas reseñas que vieron la luz con motivo de la publicación de sus libros, la labor de Perus no ha sido abordada de manera sistemática ni, menos, integral. ${ }^{5} \mathrm{El}$ presente estudio quisiera ser un primer aporte en tal dirección.

\section{Criterios de periodización y organización}

Hay buenas razones para sostener que el itinerario intelectual de Françoise Perus puede dividirse en dos grandes periodos, debiendo establecerse el parte aguas en torno a 1990. No es que aconteciera entonces una mutación radical. Tuvieron lugar, más bien, un deslizamiento de acentuaciones, una incorporación de nuevas referencias, un ajuste de tono y de vocabulario. Cabría hablar, en los términos de Egido, de una "microrrevolución semántica", en el sentido de un ajuste no estentóreo. ${ }^{6}$ Aunque cabría hacerlo solo hasta cierto

\footnotetext{
${ }^{4}$ Hartog, François, Regímenes de historicidad. Presentismo y experiencias del tiempo, México, Universidad Iberoamericana, 2007 [1 $1^{\mathrm{a}} \mathrm{ed}$. 2003]; Palti, Elías, El momento romántico. Nación, historia y lenguajes políticos en la Argentina del siglo XIX, Buenos Aires, Eudeba, 2009; Egido, Luciano, Agonizar en Salamanca: Unamuno, julio-diciembre de 1936, Barcelona, Tusquets, 2006; Schorske, Carl, La Viena de fin de siglo. Política y cultura, Buenos Aires, Siglo Veintiuno, 2011 [1 $1^{\mathrm{a}} \mathrm{ed}$. 1980]. Devés, Eduardo y Andrés Kozel, Estudios eidéticos. Una conversación desde el Sur sobre la vida de las ideas y la reconfiguración de un espacio disciplinar, Santiago de Chile, Ariadna, 2018.

${ }^{5}$ He visto las reseñas de Begoña Pulido Herráez del libro Juan Rulfo, el arte de narrar (en Latinoamérica, 56, México, 2013, 284-290) y de Armando Velázquez Soto de la antología La historia en la ficción... (en Poligrafías, Nueva Época, 1, México, 2011, 159-164); también, una más antigua de Néstor García Canclini a propósito de una obra de Alejandro Losada - La literatura en la sociedad de América Latina-, donde se hace referencia a la labor de Perus (en Cahiers du monde hispanique et luso-brésilien, 42, 1984, 184-186).

${ }^{6}$ Egido, op. cit., 34.
} 
punto, puesto que, a diferencia de lo acontecido con el último Unamuno estudiado por Egido, en el caso de Perus los deslizamientos, incorporaciones y ajustes fueron más conscientes y meditados. Veamos.

En las décadas precedentes, Perus se había identificado con los procesos de transformación social radical que despuntaban en América Latina. Es indicativo de ello que sus dos primeros libros -los dedicados al modernismo y al realismo social latinoamericanos- fueran merecedores del premio Casa de las Américas (categoría Ensayo). El empeño característico de esas primeras obras había sido el de perfilar una aproximación genuinamente materialista a la literatura latinoamericana. En esa dirección, Perus desplegó un diálogo sistemático con la tradición marxista (europea y latinoamericana). Su afán principal quedó ligado a la idea según la cual la literatura debía entenderse como una práctica ideológica específica. Buscaba alejarse tanto de las concepciones idealistas y normativas de la literatura como del carácter abstracto de las tentativas de dar forma a una "estética marxista". Claramente, su apuesta era a favor de la "investigación concreta de obras concretas". El horizonte último de su labor intelectual era político: tenía que ver con un involucramiento activo en la lucha ideológica -en la gesta del proletariado, para decirlo de modo conciso.

La revisión de la fundamental "Tercera Parte" de El realismo social en perspectiva nos permite tomar contacto con su forma de entender el proceso histórico latinoamericano así como con las principales referencias a las que acude para ubicar la entera temática de la narrativa social "en la transición de las formaciones sociales latinoamericanas de la fase inicial oligárquica y dependiente del capitalismo latinoamericano hasta otra, propiamente burguesa". ${ }^{7}$ Para Perus, es en relación con ese proceso histórico concreto que hay que entender el "requerimiento de verdad" que marca a toda esa literatura, colocándola ante desafíos formales específicos, para los cuales los escritores fueron ensayando soluciones diversas y ricas, que la historia literaria debería esmerarse por inventariar y analizar. Destacan en esas páginas las menciones a José Carlos Mariátegui, José María Arguedas, René Zavaleta, Agustín Cueva y Pablo González Casanova. Es medular el trabajo de Perus en torno a la noción "vía oligárquica y dependiente" de desarrollo del capitalismo en América Latina. A sus ojos, el resultado de transitar esa vía fue la "estructuración desigual del subdesarrollo", la cual no consiste en un mayor o menor "atraso relativo" sino en la mayor o menor "subordinación" y en la mayor o menor "alteración", en suma, en una heterogeneidad estructural que engloba múltiples niveles de contradicción.

En parte, los deslizamientos, incorporaciones y ajustes identificables a partir de 1990 se ligan a desarrollos intra-disciplinarios. Es el caso de la asimilación de los aportes de Mijaíl Bajtín por parte de los estudiosos de la literatura, Perus incluida. Pero, a la vez, y en un sentido quizá más profundo, tales movimientos son indisociables de las grandes transformaciones sociopolíticas que entonces tuvieron lugar; ante todo, el colapso de la Unión Soviética y la crisis de los demás "socialismos reales". En esos años, Perus debió enfrentar, como otros miembros de su generación, la "crisis del tiempo" derivada de tales transformaciones. En efecto, desvanecido el horizonte de la revolución socialista, tanto a escala mundial como latinoamericana, a Perus se le volvió necesario repensar el entero sentido de su quehacer. Es evidente que ajustó referentes y referencias, léxicos y

\footnotetext{
${ }^{7}$ Perus, El realismo social..., op. cit., “Tercera Parte”. La cita está tomada de la p. 179.
} 
acentuaciones, así como también el modo de concebir los vínculos entre su labor y la temporalidad.

El estudio de estas vicisitudes interesa en sí mismo, pero importa también, según adelanté, en tanto ellas constituyen una modulación específica de una dinámica más vasta de crisis conceptual y de "forzosa" adecuación a un nuevo régimen de historicidad, caracterizado, entre otras cosas, por lo que Hartog llamó el último hundimiento de la utopía. Mi hipótesis es la siguiente. Si es cierto que la "modulación Perus" de esta dinámica no estuvo exenta de autocrítica ni de incorporación de nuevos "héroes culturales", también lo es que no conllevó la renuncia a sus disposiciones críticas ni, tampoco, a sus preocupaciones éticas. Lejos de ello, en un determinado nivel, cabría caracterizar a la "modulación Perus", como la admisión de una "derrota política" imposible de ser negada, mientras que, en otro nivel (más "profundo", si cabe la expresión), se la podría describir como el despliegue de una suerte de pertinacia soterrada o camuflada de un pathos crítico matricial, cuyos términos primordiales no se vieron alterados en lo sustantivo en esa "crisis del tiempo".

En lo que respecta a la organización de la obra de Perus, quizá convenga postular que la misma está conformada por textos de coloración más eminentemente teórica y por "investigaciones concretas de obras concretas". La interrelación entre estos planos es estrechísima; de hecho, algunos de sus textos "teóricos" más emblemáticos son las introducciones, tanto a sus investigaciones concretas como a las antologías que preparó. Con todo, no parece excesivo postular la presencia de esas dos grandes "familias" de textos. Las aportaciones más "teóricas" de Perus son indisociables de una reflexión continua acerca de la historia y los alcances de su disciplina, considerada en sus relaciones con otras disciplinas y con los sucesivos contextos sociopolíticos. Por su parte, y según adelanté, sus "investigaciones concretas de obras concretas" han privilegiado el análisis de la literatura hispanoamericana del siglo XX; en particular, de la que antecedió al denominado boom: Ricardo Güiraldes, José Eustasio Rivera, Rómulo Gallegos, Jorge Icaza, Agustín Yánez, Miguel Ángel Asturias, Juan Rulfo, Rosario Castellanos; también, José María Arguedas, Édouard Glissant... Por último, en relación con la conformación de una mirada teórica sobre la producción literaria latinoamericana, interesa tener presente la dimensión polémica de sus aportes: Perus ha debatido, puntualmente, con Emir Rodríguez Monegal y con Ángel Rama (también con Ana Pizarro), mostrándose más próxima a los desarrollos de Antonio Cornejo Polar. En términos generales, sus escritos trasuntan una disposición marcadamente inconformista, tanto frente a las realidades sociales y culturales como ante las orientaciones predominantes en las disciplinas sociales y humanas. Mi acercamiento a su obra busca precisamente poner de relieve la pertinacia de esa disposición, de ese inconformismo.

\section{Principales aportes teóricos}

El entramado hipotético que presento a continuación es esquemático y provisional; quizá posea, con todo, cierta utilidad heurística, que será preciso calibrar en ulteriores asedios. Hacia 1993, Perus decide volver a publicar su libro sobre el realismo social. Lo hace modificando ligeramente el título y anteponiendo un "Prólogo" que de alguna manera es una puesta al día de sus posiciones. Dicho "Prólogo" es importante: se aprecian ajustes y asimilación de novedades -señaladamente, Paul Ricœur y Mijaíl Bajtín-, aunque insistiendo 
en la vigencia de una serie de preocupaciones y opciones primordiales. Refiriéndose al libro publicado en 1982, escribe en 1993:

[La] conceptualización, lo mismo que la perspectiva de análisis y la forma de la exposición, llevan desde luego el sello de la época en que el libro fue concebido y la investigación, llevada a cabo. Su lenguaje, apoyado en una tradición entonces dinámica y viva, la confianza en la posibilidad del cambio social que anima la perspectiva, y el intento de romper con la compartimentación estanca entre historia y literatura, pueden aparecer hoy ingratos y hasta ingenuos. Sin embargo [...], sigo pensando que [...] el trabajo no ha perdido toda su validez. ${ }^{8}$

En su laconismo -son apenas cinco páginas-, este "Prólogo" de 1993 ofrece pistas para entender los cambios: en el pasaje antecitado, son muy significativas las cláusulas "pueden aparecer hoy" y "sigo pensando que". Sin embargo, y pese a su importancia, este texto dista de agotar los múltiples aspectos implicados. Para poder avanzar es preciso considerar también otros aportes, previos y posteriores.

Uno, ligeramente anterior, es el estudio sobre Canaima. En sus pasajes iniciales, Perus ofrece una síntesis potente, tanto de sus tesis generales sobre el realismo social (y, dentro de él, sobre la llamada "novela de la tierra"), como de las premisas teórico-metodológicas en las que se basa su análisis de la novela de Gallegos. Lo más notable es la aparición de la noción de poética, ausente en sus primeros libros. Además de ser indicativa de la asimilación de los aportes de Bajtín, la noción parece desempeñar la "función" de nexo entre dos énfasis preexistentes: el colocado en la condición de forma-sens de los textos literarios -que remite a la noción de modelización artística, retomada de Yuri Lotman-, y el puesto sobre la heterogeneidad estructural latinoamericana -tanto en lo que respecta a los elementos culturales como a las formas narrativas. Para Perus, la superposición conflictiva de elementos culturales heterogéneos (que a ella le recuerda el plurilingüismo mentado por Bajtín), tiene lugar en América Latina sobre un telón de fondo caracterizado por un grado relativamente bajo de dialogismo social. Este motivo de la heterogeneidad sin dialogismo es no solo clave sino además persistente: se lo vuelve a encontrar, dos décadas después, en el núcleo de su abordaje de la obra de Juan Rulfo. Más acá de esto, tras revisar el estudio sobre Canaima -así como el contemporáneo dedicado a la novela Al filo del agua-queda claro que, en Perus, cada texto literario está regido por una poética específica, en virtud de la cual se modeliza un mundo concreto, se articulan tradiciones culturales y formas narrativas heterogéneas y se propone algún tipo de solución a los problemas gnoseológicos y éticos que se plantean. ${ }^{9}$

Otro aporte clave, algo posterior al prólogo de 1993, es su ensayo dedicado a pensar la propuesta de Bajtín desde América Latina, publicado en 1995. Perus establece allí vinculaciones entre dicha propuesta y dos aproximaciones latinoamericanas a la literatura y a la cultura a las que concibe como instancias protagónicas de una "tradición" (o "perspectiva") "autocentrada" y también, en cierto modo, como bajtinianas avant la lettre: la de Cornejo Polar y la de Rama. Definida en los primeros pasajes del texto, la noción de "perspectiva autocentrada" es importante. También lo son aquellas zonas del ensayo

\footnotetext{
${ }^{8}$ Perus, El realismo..., op. cit., III-IV.

${ }^{9}$ Perus, "Universalidad del regionalismo...” y "La poética narrativa de Agustín Yáñez...”, cit.
} 
orientadas a esclarecer cuál es el tipo de asimilación de los aportes de Bajtín que propone Perus. Esto concierne ante todo a cómo entender la noción de dialogismo. De acuerdo con Perus, las interpretaciones vigentes de esa categoría crucial tienen efectos cuestionables, ya que

...al desvincular el análisis estilístico de la preocupación central de Bajtín por sentar las bases de una poética histórica (al menos por lo que se refiere a la novela), se traslapan ámbitos y niveles de pertinencia, se restringe y debilita el valor heurístico de la noción de dialogismo, y se desemboca en un reduccionismo formalista que vuelve a tergiversar los problemas relativos al ámbito decisivo de la forma.

Y enseguida:

Quisiera sostener aquí que la noción de dialogismo sienta ante todo la existencia de una zona fronteriza entre espacios socioculturales y sociolingüísticos diversos y relativamente inestables que obedecen a temporalidades disímiles, y cuyas delimitaciones y modalidades específicas de articulación histórica y literaria constituyen precisamente el objeto central del "principio dialógico" bajtiniano. ${ }^{10}$

Sostiene Perus que la propuesta de interpretación de la novela indigenista delineada por Antonio Cornejo Polar -que, en contraste con el modelo goldmanniano de la novela, destaca por su inestabilidad formal, prefigurada a su vez en las crónicas de Indias-, presenta una profunda similitud con el dialogismo bajtiniano. En palabras de Perus:

Supongo que a nadie escapa la profunda similitud que, a pesar de las diferencias de fuentes conceptuales y de terminología, une la propuesta de Cornejo al dialogismo bajtiniano. Debo añadir incluso que esta propuesta, anterior a mi encuentro con la obra de Bajtín, es la que ha guiado en gran medida mi lectura de la obra de Bajtín y me ha llevado a una apreciación de los alcances de dicha obra algo distinta de las que, paradójicamente, provienen del estructuralismo y quisieran emparentar a Bajtín con la filosofía posmoderna. ${ }^{11}$

Esta revelación es sumamente interesante desde el punto de vista del estudio de los procesos de recepción: una crítica de origen francés, a esa altura plenamente "latinoamericanizada", lee a Bajtín guiada en gran medida por los señalamientos de Cornejo Polar. Perus también encuentra un parentesco entre la noción de transculturación narrativa, recreada por Ángel Rama a partir de los aportes de Fernando Ortiz, y algunas nociones medulares de Bajtín. A Perus le atrae la concepción dinámica de la heterogeneidad cultural planteada por Rama. Escribe:

\footnotetext{
${ }^{10}$ Perus, Françoise, "El dialogismo y la poética histórica bajtinianos en la perspectiva de la heterogeneidad cultural y la transculturación narrativa en América Latina", en Revista de crítica literaria latinoamericana, 21, $1995,34$.

${ }^{11}$ Idem, 38-39.
} 
En esta definición de la "transculturación", y en particular en el problema del contacto, o de la ausencia de contacto, entre los "dos frentes culturales" de los que habla aquí el autor [Rama], pueden ubicarse sin mayores dificultades, el plurilingüismo, la heteroglosia y el dialogismo bajtinianos. ${ }^{12}$

El panorama de esos años se torna más completo si se revisan dos aportes más. De un lado, la "Introducción" a la antología titulada Historia y literatura, de 1994; de otro, la “Introducción" teórica a De selvas y selváticos, publicada en 1998. La "Introducción" de 1994 permite asomarse a los principales términos de su asimilación de los desarrollos de Paul Ricœur y de Michel de Certeau, así como de su balance de las vicisitudes de la sociocrítica, representada en la antología por textos de Régine Robin y Edmond Cros. Escribe allí Perus:

En lo que hemos concebido como un cruce de perspectivas entre el historiador y el literato para la iluminación de aquel espacio fronterizo, de demarcaciones y geografía inciertas, nos ha guiado una serie de opciones. La primera y fundamental ha sido la de buscar autores y textos "propositivos", esto es, autores y textos que, sin desconocer el ya viejo malestar en nuestra cultura y el clima de nihilismo o dimisión que envuelve actualmente las ciencias sociales y las humanidades, se inscriban deliberadamente en contra. Con ellos, hemos querido reafirmar la posibilidad y el valor del conocimiento en la cada vez más necesaria recreación de la cultura. Pese a la diversidad de sus formaciones intelectuales y de sus posiciones, es notorio el vínculo de todos los autores con la tradición del humanismo europeo (en muchos sentidos, reñido con el pragmatismo y el escepticismo anglosajones), y es particularmente sensible también el nexo que establecen entre las cuestiones de orden epistemológico y las preocupaciones éticas. ${ }^{13}$

Hay varios elementos para retener aquí. El primero es el diagnóstico sobre la situación de las ciencias sociales y las humanidades, que exige plantearse la recreación de la cultura desde el conocimiento. El segundo es la voluntad de identificar formulaciones no nihilistas, sino propositivas, constructivas. El tercero es la reivindicación de la tradición del humanismo europeo, pensado como distinto y contrapuesto a las tradiciones del pragmatismo y el escepticismo anglosajón. Estos tres elementos son perfectamente expresivos de la experiencia de la crisis del tiempo.

En esta misma línea de reflexión, interesa destacar el acercamiento de Perus a los desarrollos de Paul Ricœur; muy especialmente, en lo que concierne a cómo pensar la temporalidad una vez "descartado Hegel" (y la noción de la "mediación total"), así como a su llamado, basado en la asimilación de un par categorial retomado de Reinhart Koselleck, a indeterminar nuestro espacio de experiencia (a reabrir el pasado, exhumando sus promesas incumplidas, incluso destrozadas...) y a determinar nuestro horizonte de

\footnotetext{
12 Idem, 43.

${ }^{13}$ Perus, Françoise (comp.), Historia y literatura, op. cit., "Introducción”, 13.
} 
expectativas. Para reconstruir y articular pormenorizadamente esta serie de deslizamientos, incorporaciones y ajustes es fundamental considerar la "Introducción" de 1998. ${ }^{14}$

En los años subsiguientes, Perus se movió dentro de los parámetros establecidos en la constelación de elaboraciones recién comentadas. Esto no significa que no haya habido novedades. Las hubo. Menciono seis. Primera, el balance crítico de La ciudad letrada de Rama, el cual se articula con su convocatoria a "defender la tradición letrada". 15 Segunda, su insistencia en robustecer la "perspectiva autocentrada" para pensar América Latina. ${ }^{16}$ Tercera, la integración de Jacques Rancière a su galería de referentes (verificable desde al menos 2009). Cuarta, la nueva antología -en cuya factura ocupa un lugar destacado la asimilación de un libro de François Cusset. ${ }^{17}$ Quinta, la publicación del demorado y admirable estudio sobre (la poética narrativa de) Rulfo. Sexta, la culminación de Transculturaciones en el aire, balance integrador cuyo título denota la aludida doble filiación en el Rama de Transculturación narrativa (y, por esa vía, en Fernando Ortiz) y en el Cornejo Polar de Escribir en el aire. ${ }^{18}$ Este por ahora último libro contiene varios elementos de interés teórico. Refiero entre ellos el refinado análisis del libro clásico de Fernando Ortiz, el contrapunto polémico con Ana Pizarro en torno a los criterios para perfilar una historia de la literatura latinoamericana, la esclarecedora "conversación" con los planteamientos de Jacques Rancière, el impresionante cotejo entre la interpretación de Pedro Páramo por Rama y por la propia autora...

Su "ajuste de cuentas" con La ciudad letrada, dado a conocer en 2005, es relevante por varias razones. El problema principal visualizado por Perus es que las implicaciones de la noción "ciudad letrada" contribuyeron al proceso de desmantelamiento de las tradiciones letradas, en nombre de la reivindicación de unas "identidades subalternas" eventualmente emergentes y supuestamente auténticas. Según Perus, es un equívoco riesgoso postular que la tradición letrada-culta es exclusiva de las "elites", tanto como lo es pensar que no es más que un dispositivo funcional a la reproducción de los poderes establecidos. Tampoco es adecuado oponer simplificadoramente un "Occidente" pensado como entidad monolítica a unas culturas vernáculas "auténticas". En lugar de ello, sería más productivo concebir a la tradición letrada como un conjunto de legados diversos y complejos, al que cada uno tiene el derecho de acceder para disfrutarlo y reelaborarlo. Son consideraciones que empalman

\footnotetext{
${ }^{14}$ Perus, De selvas y selváticos..., op. cit., "Introducción”, 17-42.

15 Perus, Françoise, “QQué nos dice hoy La ciudad letrada de Ángel Rama?”, en Revista Iberoamericana, Pittsburgh, 71, 2005, y "En defensa de la tradición letrada", en Norma de los Ríos e Irene Sánchez, América Latina: historia, realidades y desafios, México, FFyL-UNAM, 2005.

${ }^{16}$ Perus, "Los Estudios Latinoamericanos...", op. cit.

${ }^{17}$ Perus, (comp.), La historia en la ficción, op. cit. El libro de Cusset es French Theory. Foucault, Derrida, Deleuze \& Cia, y las mutaciones de la vida intelectual en Estados Unidos, Barcelona, Melusina, 2005 [1 ${ }^{\mathrm{a}}$ ed. 2003].

18 Perus, Transculturaciones..., op. cit. El título escogido por Perus combina referencias a Rama, Ángel, Transculturación narrativa en América Latina, México, Siglo Veintiuno, 1985 [1982] y a Cornejo Polar, Antonio, Escribir en el aire. Ensayo sobre la heterogeneidad socio-cultural en las literaturas andinas, Lima, Latinoamericana Editores/CELACP, 2003 [1994]. Como explicaré enseguida, en los últimos años Perus profundizó su distancia crítica con respecto a ciertas zonas de la obra de Rama, mientras que se mantuvo próxima a las formulaciones de Cornejo Polar. Para Perus, la asimilación de los aportes de Cornejo por parte de la crítica es todavía insuficiente. Quienes se interesen por estas cuestiones pueden revisar también Sobrevilla, David, "Transculturación y heterogeneidad: avatares de dos categorías literarias en América Latina", en Revista de crítica literaria latinoamericana, Lima-Hanover, núm. 54, 2001, pp. 21-33, entre otros materiales.
} 
con las de la "Introducción" a la antología de 1994 y, también, con las que podemos encontrar en el texto que introduce la segunda parte de la antología de 2009. Escribe allí Perus:

En la primera parte de esta obra hemos ofrecido algunos ejemplos paradigmáticos -o sintomáticos- de las transformaciones que se llevaron a cabo en la concepción y análisis de la cultura, acudiendo a tres autores franceses de formación diversa [Barthes, Foucault, Derrida], no sin recalcar el papel que en su notoriedad había desempeñado su paso por las universidades estadounidenses, en donde fueron leídos a medias y fuera de contexto, y reinterpretados en función de imperativos más ideológicos que propiamente científicos y humanísticos. De esta "mala lectura" provienen una serie de tópicos sumamente dudosos, que andan por el mundo -el muy latinoamericano nuestro incluido- y convierten a la "cultura occidental" -entiéndase la europea, cuando no simplemente la francesa- en el "colmo de los males": en la encarnación de la metafísica de lo Uno, de los binarismos excluyentes, de la negación y la dominación del otro, de la "Razón cartesiana", de la cuna de los totalitarismos "ilustrados", con sus empresas de dominación colonial y sus holocaustos. Todo abstraído, revuelto y denostado desde un parti pris de ignorancia, desconocimiento o soberbia. De ahí la proliferación de los "pos" [...] Sirva entonces esta pequeña muestra para devolver a nuestros lectores aunque sea el sentimiento de que el Occidente europeo es algo más, y algo bastante distinto de la caricatura espectral y grosera que de él han echado a rodar y anda rondando por ahí. ${ }^{19}$

Este pasaje es altamente revelador. Porque explica el sentido de la antología -la cual, vale la pena aclararlo, no es una reedición de la titulada Historia y literatura, aparecida en la década anterior, sino que es una obra distinta-, pero también porque recupera como pocos la orientación y el tono hablado por Perus en sus seminarios de posgrado y en diversas modalidades de intercambio conversacional. Distante de las modas y de los "giros", de las profusas aplicaciones de los prefijo "pos/" de" y, esto es crucial, de los cuestionamientos en bloque a la tradición humanista, en el último cuarto de siglo Perus ha venido advirtiendo sobre el peligroso coqueteo con el irracionalismo implicado en todas esas disposiciones. De acuerdo con Perus, de la gravísima crisis planetaria se sale -si es que se sale- no transitando retóricas políticamente correctas, sino por el cultivo apropiado del conocimiento, de la ciencia y del legado humanista. Estas orientaciones, sumadas a su sarcasmo ante buena parte de los tópicos políticamente correctos y de los íconos intelectuales de moda, han propiciado que algunos estudiantes y colegas distraídos tildaran a Perus de "eurocéntrica". Esta absurda imputación desconoce injustamente su insistencia en el cultivo de una perspectiva autocentrada -"América Latina ha de ser para sí su propio 'centro', y dejar de concebirse a sí misma como simple 'periferia', colonial o no", escribió, en forma

\footnotetext{
${ }^{19}$ Perus, (comp.), La historia en la ficción ..., op. cit., 225-226.
} 
contundente, en ese mismo momento-, ${ }^{20}$ así como sus múltiples y originales aportes a la dilucidación de nuestra historia cultural.

Más allá de esto, me interesa insistir sobre el hecho de que en los últimos veinte o veinticinco años no se aprecia en la obra de Perus ninguna dinámica de adecuaciones, revisiones o ajustes más o menos masivos -es decir, no se verifica ninguna "revolución semántica" (ni micro ni macro)- equivalente o análoga a la que tuvo lugar en la primera mitad de la década de 1990.

Complementariamente a lo antedicho, hay algunos elementos de la primera etapa de su itinerario que interesa recordar. Por dos razones. Porque no desaparecieron en la fase subsiguiente y porque se trata de cuestiones de gran importancia teórico-metodológica. En mi opinión, su permanencia resulta indicativa de la pertinacia soterrada o camuflada que, según vimos, hay implicada en la "modulación Perus" de procesamiento de la crisis del tiempo.

Uno de esos elementos es la actitud de rescate de la tradición literaria latinoamericana, a la que Perus invita a revisar y valorar de manera integral. Así, por ejemplo, refiriéndose a las posiciones críticas "formalistas" sobre Don Segundo Sombra, las cuales solían tematizar sus "aberraciones formales" o "fallas estructurales", escribía en 1982:

El atribuir, como lo hace generalmente la corriente crítica en cuestión, la hibridez o heterogeneidad formal de la obra a una supuesta insuficiencia en su concepción artística no demuestra más que las insuficiencias de la crítica misma: al desvincular los problemas de forma de los de la conformación artística de un material de ideas y representaciones histórica y socialmente dado, que como tal tiene su propia "resistencia" (materialidad), la crítica no tiene otro recurso que el de acudir a concepciones formalistas y normativas, con respecto a las cuales toda obra literaria tiene necesariamente que resultar "impura". ${ }^{21}$

Toda la discusión con Rodríguez Monegal en torno a la significación del realismo social concierne a esta crucial cuestión.22 Bastante antes de 1990, Perus pensaba que dar cuenta de unas formas huidizas, difíciles de ubicar en los casilleros de los manuales de historia literaria, constituye uno de los desafíos mayores de una crítica latinoamericana genuina. Por supuesto, su propuesta de valoración integral de la tradición literaria latinoamericana es incompatible con toda propensión a cercenar de la misma, en nombre de puntos de vista normativos basados en concepciones del lenguaje discutibles, una franja tan significativa como el realismo social. Para Perus, esas formas esquivas y singulares son indicativas, no tanto de insuficiencias o limitaciones, cuanto de meditadas decisiones artísticas. Su análisis de La vorágine, prefigurado en el libro de 1982 y magistralmente acabado en el de 1998, también es ejemplar en este sentido. En efecto, a sideral distancia de quienes señalaron peyorativamente la heterogeneidad formal de la novela de Rivera, el anacronismo del romanticismo que signa su primera parte, la inconsistencia de Arturo Cova (el protagonista), y las "fallas" estéticas de las partes segunda y tercera, Perus invita a

\footnotetext{
${ }^{20}$ Perus, Françoise, “Los Estudios Latinoamericanos: ¿de nueva cuenta en busca de sí mismos?”, en Nostromo, revista crítica latinoamericana, México, 2, 2009, 8.

${ }^{21}$ Perus, El realismo social..., 196.

${ }^{22}$ Idem, 73 y ss.
} 
distinguir al autor ficticio del narrador y protagonista -para percibir planos, distancias, incluso sarcasmos- y a prestar atención al doble marco interpretativo sentado por la "vorágine" y la "violencia". Para Perus, esta novela, "...no consiste en el encuentro de la civilización con la naturaleza y el mito, sino en el de una cultura, cimbrada por las violentas transformaciones que sufre, con su propio inconsciente, simbolizado por los multísonos ecos que de sí misma le devuelve la selva." 23 No es excesivo ver en todo esto nítidas antecedencias del acento colocado en la "perspectiva autocentrada".

Muy ligado a lo anterior, se verifica ya entonces el despliegue de una modalidad de lectura que, aunque no se auto-designa todavía con esas palabras, anticipa claramente lo que luego aparecerá nombrado como examen de las "poéticas narrativas". Se trata, en lo fundamental, de una lectura "de cerca" o "compenetrada", consagrada a identificar, en cada obra, el núcleo de contradicciones que la organiza, los nudos narrativos y semánticoformales, las cadenas de oposiciones y semejanzas, las redes metafóricas, los manejos de los pronombres personales y de las personas verbales, el tratamiento de las voces, la relación con géneros previos, la presencia de elementos de la tradición cultural (latinoamericana y no), la dialéctica entre las propiedades del referente, del material ideológico-cultural, del proyecto ideológico-estético del/a autor/a. En Perus, lo que tiene lugar en un texto medianamente elaborado pocas veces, sino nunca, se debe a la casualidad... Hay un autor que propone algo desde cierto proyecto, y para que haya "obras" debe haber lectores competentes, es decir, capaz de encarar el imprescindible trabajo de decodificación transcultural. Por lo que no se exagera nada si se afirma que, como Cornejo y como Rama, también Perus fue bajtiniana avant la lettre.

\section{Intersecciones, proyecciones}

Con respecto a los vínculos entre el enfoque perusiano y el estudio de elaboraciones textuales no ficcionales, debiera ser a esta altura evidente que considero tales vínculos posibles, necesarios, estimulantes. Pienso, como mínimo, en la conveniencia de desplegar en nuestras aproximaciones a los "ensayos de ideas" varios de los énfasis mencionados. Primero, la noción de "perspectiva autocentrada". Segundo, el acento en la "propuesta/proyecto" autoral, que solicita la lectura "de cerca" o "compenetrada", sensible tanto a la modelización y a la forma artística como a los acentos, matices y espesores de las voces que surcan las elaboraciones (¿cabe hablar de "poética narrativa" al abordar ensayos de ideas?, ¿de no, a qué otra noción, más precisa, podría acudirse...?). Tercero, la puesta de relieve de la doble necesidad de reabrir el pasado y de determinar mejor nuestras esperas y en la necesidad derivada de propiciar el diálogo entre los espacios de experiencia y el horizonte de expectativas de los lectores y de los textos. Cuarto, la insistencia en la necesidad de fortalecer la formación cultural de los lectores ante la embestida de la industria del imaginario de masas. Quinto, el llamado a eludir los cantos de sirena de una corrección política que, las más de las veces, es crítica solo en apariencia.

En un nivel de mayor abstracción, este haz de acentos podría condensarse en una única fórmula: la defensa de la tradición letrada. Bien entendido el punto, no parece excesivo sostener que la "modulación Perus" del procesamiento de la crisis del tiempo desembocó en el llamamiento, de talante cuasi-belicoso, contenido en dicha fórmula. De

\footnotetext{
${ }^{23}$ Perus, De selvas y selváticos..., op. cit.
} 
acuerdo con Perus, el cultivo apropiado de la tradición letrada permite entre otras cosas apreciar los hallazgos y los límites de las culturas en sus relaciones con la/s alteridad/es. En su perspectiva, como ya sabemos, las sociedades latinoamericanas aparecen caracterizadas no solo como heterogéneas y conflictivas, sino además como de bajo dialogismo. Textualizaciones como las estudiadas por Perus no "reflejan" apenas ese cuadro, sino que lo elaboran, en el sentido de que ofrecen representaciones más o menos formalizadas de unas relaciones sociales señaladamente conflictivas, abriendo así posibilidades de dialogismo -y de reflexión sobre sus límites, lo cual no es menos significativoque implican, por fuerza, al lector. Todo esto invita a problematizar experiencias, a determinar expectativas, a reabrir promesas, en la línea propuesta por Ricœur/Koselleck. Escudriñar sistemáticamente estas dimensiones, en su espesor (discontinuo) y en sus pliegues, sería la tarea de la historia de la literatura. También podría serlo, con los ajustes del caso, de la historia del pensamiento.

¿No es el diagnóstico de Perus, pese a su invitación a revisar preferentemente formulaciones no nihilistas, es decir, propositivas y constructivas, un diagnóstico pesimista? ¿No hay algo de decadentismo cultural en su mirada sobre la sociedad y la cultura contemporáneas? Es probable que así sea. En realidad, el pathos perusiano no parece muy alejado del pathos del último Castoriadis quien, también en los años noventa, decía:

Este retorno del conformismo es un retorno general de la heteronomía. He definido la heteronomía como el hecho de pensar y actuar como lo exigen la institución y el medio social (abiertamente o de un modo subterráneo). Ahora bien, actualmente (...), nadie parece estar en condiciones de cuestionar el final de la filosofía o de decir que lo que se presenta como pintura es nulo en la mayoría de los casos; digo nulo, no digo mediocre o simplemente aceptable. Si alguien se atreve a semejante discurso, será tildado de beocio, incapaz de comprender el arte, o bien de viejo que se rehúsa a aceptar la evolución de la historia. El conjunto de estos hechos, si tienen cabida para nosotros y si acordamos globalmente con la interpretación que propongo de ellos, traduce una crisis de la institución general de la sociedad y de las significaciones imaginarias sociales. Como ya lo indiqué, esta crisis no es incompatible con una continuación de los progresos de la tecnología y de la producción, de la erudición e incluso de la ciencia (...) Pienso que estamos en una encrucijada de caminos de la historia, de la gran historia. Un camino ya aparece claramente trazado, en todo caso en lo que se refiere a su orientación general. Es el camino de la pérdida de sentido, de la repetición de formas vacías, del conformismo, de la apatía, de la irresponsabilidad y del cinismo, junto con el creciente dominio del imaginario capitalista de expansión ilimitada de un control racional, seudo control seudo racional de la expansión sin límites del consumo por el consumo, o sea por nada, y de la tecnociencia autónoma en su curso, que forma parte, evidentemente, de la dominación de este imaginario capitalista. Otro camino debería abrirse: no está trazado de ningún modo. Puede abrirse únicamente a través de un despertar social y político, un renacimiento, un nuevo resurgir del proyecto de 
autonomía individual y colectiva, es decir, de la voluntad de libertad. Esto exigiría un despertar de la imaginación y del imaginario creador. ${ }^{24}$

¿Cómo valora Perus la literatura, las creaciones artísticas y las ideas que se producen en nuestros días? ¿Poseen esta literatura, estas creaciones y estas ideas un nulo valor, parecidamente a la pintura que (no) valoraba Castoriadis en la intervención recién citada?

Podría pensarse que el esmero por acopiar fórmulas constructivas y propositivas, detectable en Perus a partir de su vivencia de la "crisis del tiempo", es precisamente un modo de procesar esa crisis, de conjurar, al menos en parte, la melancolía y el desasosiego. La coherencia que cabe identificar en Perus no es en absoluto naíf, sino que es una coherencia de coloración trágica. Su manera de transitar la crisis del tiempo enseña, entre otras muchas cosas, que es posible atravesar una encrucijada así sin mea culpas estentóreas, sin contorsiones oportunistas, sin transfiguraciones vergonzantes, sin concesiones al cinismo, en suma, sin traicionar(se). No es el único caso, desde luego. Aun así, es un caso remarcable, entre otras cosas por haber acompañado el proceso con una intensa reflexión sobre la problemática de la temporalidad. Esa reflexión suya nos ayuda a plantearnos mejor una serie de cuestiones; con todo, no las resuelve a todas, y nos coloca ante desafíos nuevos.

El pasaje siguiente ilustra a la perfección el pathos perusiano, en su combinación de crítica (una crítica reforzada por un uso muy personal de las comillas), melancolía y obstinación por recuperar unas promesas desplegadas en un pasado no tan remoto (parte de las cuales están destacadas en el pasaje, en itálica, por la propia autora). Se trata de un pathos de poderosa significación ética, como lo patentizan las reflexiones de las líneas finales sobre la dificultad de nuestras sociedades para encarar adecuadamente la cuestión de la alteridad. La cita es extensa, vale la pena leerla con detenimiento:

En efecto, las relaciones de un "público" enfrentado al "libre consumo" de mercancías -eufemísticamente bautizadas de "bienes culturales"- se distingue fundamentalmente del que venían formando las instituciones educativas públicas, ligadas al Estado republicano. Tan mal que bien, estas instituciones habían logrado convertir al legado cultural en su conjunto, y al literario en particular, en un bien público sujeto a toda clase de debates, tanto dentro de ellas como en el marco de lo que se podía definir, siguiendo en esto a Bourdieu, como el "campo literario". El "público" actual en cambio se halla en buena medida desprovisto de referencias estables y de instrumentos conceptuales que le permitan elaborar reflexivamente su relación, ya no con un legado y sus tradiciones, sino con unos "objetos" pulverizados y desconectados entre sí. Ciertamente, no han desaparecido las instituciones educativas ni su afán formativo. Sin embargo, a nadie escapa su actual debilitamiento -en particular en el ámbito de las Humanidades- ni la profunda crisis de "identidad" que aqueja a las disciplinas humanísticas y sociales. La privatización insidiosa de una enseñanza cada vez más requerida por "el mercado", por un lado, y el sometimiento de la población escolar al imperio de la industria mediática, por el otro lado, no son ajenos a esta crisis de "identidad": promueven de hecho

${ }^{24}$ Castoriadis, Cornelius, "Imaginario e imaginación en la encrucijada". En Figuras de lo pensable. Buenos Aires, FCE, 2001, 108-109. 
todas las modalidades del "disfrute" y de identificación subjetiva con la imagen -en toda la extensión de la palabra-, en contra de cualquier aprendizaje de una disciplina intelectual y del esfuerzo que supone la formación para la reflexión crítica y creativa; como si éstos fueran adversos a cualquier "satisfacción" y no brindaran a la sensibilidad y al intelecto la posibilidad de "goces" mayores y más duraderos. Un imaginario "líquido" tiende así a reemplazar el trabajo de distinción y elaboración subjetiva de los conflictos entre lo real y su representación en y por el lenguaje -o mejor dicho, los lenguajes-, con la consiguiente deriva hacia la cristalización de "identidades" enclaustradas, incapaces de concebir la alteridad más allá de la diferencia. Estas identidades diferenciales -y los "derechos" de cada una de ellas a afirmarse en su "diferencia" - ocupan así todo el espacio de "lo social", al que definen sin referencia a ninguna sociedad concreta, ni a las dimensiones propiamente políticas -y no simplemente jurídicas- de su organización y sus orientaciones. El "mercado" y sus "leyes" pueden así aparecer como naturales -curiosamente tan "libres" como inexorables-, tanto como las catástrofes humanas y sociales hoy a la vista de todos...25

A los ojos de Perus, las tendencias prevalecientes en la sociedad actual (latinoamericana, sí, pero no de manera exclusiva, como deja ver el pasaje) están a sideral distancia de dar solución a los bajos niveles de dialogismo social y de debate público. Sería difícil que el resultado fuera otro, dada la citada propensión a la cristalización de unas "identidades enclaustradas", incapaces de concebir la alteridad de otro modo que el de la seudo-celebración de la "diferencia". Se trata, como podemos apreciar, de reflexiones que, no sin pesar, critican y denuncian, pero que, también, por ese extraño contraste que suelen activar las meditaciones distópicas o filo-distópicas, no dejan de perfilar anhelos y esperanzas.

\section{Apreciación}

Hemos identificado en Perus un remarcable énfasis en cultivar una perspectiva latinoamericana "autocentrada". Hasta donde alcanzamos a ver, esta expresión aparece por vez primera en un texto suyo de mediados de la década de 1990; sin embargo, como disposición, ya estaba presente desde antes, siendo la raíz de su característica mirada de la literatura y la cultura latinoamericanas como interesantes y valiosas a priori. Este énfasis va ligado a una caracterización de las sociedades latinoamericanas que pone de relieve su heterogeneidad estructural y la índole trunca y discontinua de sus tentativas de modernización, en una historia marcada por la conquista, la colonia y la dependencia. Se trata, según vimos, de una heterogeneidad conflictiva con un bajo grado de dialogismo social.

Hemos identificado, también, un modo de abordar los textos que centra la atención en el examen de las "poéticas narrativas concretas". Parecidamente a lo sucedido con el énfasis anterior, la noción emerge a principios de la década de 1990; empero, en tanto

\footnotetext{
${ }^{25}$ Perus, Françoise, "Leer no es consumir (la literatura latinoamericana ante la globalización)", en Revista de crítica literaria latinoamericana, Lima-Hanover, 69, 2009, 20-21.
} 
disposición, estaba presente desde antes. Se trata de un aspecto clave, que empalma con el fuerte acento colocado en las propiedades artísticas de los textos literarios, en su condición de forma-sentido, en la modelización (Lotman), en la propuesta del autor, en su proyecto estético e ideológico. Perus no niega la importancia de la recepción, pero se resiste a hipostasiar la figura del lector; como ya sabemos, uno de sus motivos predilectos es el de poner de relieve la necesidad de robustecer la formación artística de los lectores, entendida en buena medida como su capacidad para la decodificación transcultural de propuestas que poco tienen de contingentes.

Comprobamos igualmente que, a partir de circa 1990, se verifica en Perus una reelaboración del modo de concebir la temporalidad, vía la asimilación de aportes de Ricœur/Koselleck. Estrechamente vinculado a ello, se detecta un movimiento orientado a la defensa de la tradición letrada y, más ampliamente, de la tradición humanista. La integración de este conjunto de disposiciones habilitó una "microrrevolución semántica" (en su caso consciente y meditada) que le permitió procesar, por medio de una modulación específica, la "crisis del tiempo" asociada al último hundimiento de la utopía. Las novedades de los últimos lustros (entre las cuales se cuenta su distancia crítica ante ciertas zonas de la obra de Ángel Rama) se dejan integrar sin mayor problema en la matriz forjada en aquellos años de reacomodamientos forzosos. Dichas novedades constituyen sucesivas respuestas ante lo que a sus ojos no son más que "engañosas falacias" de nuestro tiempo (el de la llamada "globalización") y de su correspondiente régimen de historicidad: la cancelación de las experiencias pasadas, la desorbitada apertura del futuro, la proliferación de prefijos, gestos y retóricas políticamente correctos pero vacuos, los riesgos de naufragar en el irracionalismo. Hemos visto, finalmente, que, aun si se refieren en principio al quehacer de la historia y la crítica de la literatura, las propuestas y las acentuaciones de Perus poseen interés y relevancia, también, para quienes se interesan en el estudio de elaboraciones textuales no ficcionales.

\section{Bibliografía}

\section{Obra selecta de Françoise Perus}

Transculturaciones en el aire. En torno a la cuestión de la forma artística en la crítica de la narrativa hispanoamericana, México, UNAM, 2019.

Juan Rulfo, el arte de narrar, México, UNAM, 2012.

"Orientalismo y occidentalismo en la escritura de Facundo de Domingo F. Sarmiento", en Cuadernos Americanos, México, 139, 2012, pp. 105-116.

“Los Estudios Latinoamericanos: ¿de nueva cuenta en busca de sí mismos?”, en Nostromo, revista crítica latinoamericana, México, 2, 2009, pp. 7-11.

"Leer no es consumir (la literatura latinoamericana ante la globalización)", en Revista de crítica literaria latinoamericana, 69, Lima-Hanover, 2009, pp. 11-31.

(Comp.) La historia en la ficción y la ficción en la historia. Reflexiones en torno a la cultura y algunas nociones afines: historia, lenguaje y ficción, México, IIS-UNAM, 2009.

“¿Todavía tiene sentido la historiografía literaria?”, en Anuario del Colegio de Estudios Latinoamericanos 2007, México, 2, 2008, pp. 59-65. 
"Antonio Cornejo Polar, una política de la lectura", en Anuario del Colegio de Estudios Latinoamericanos 2006, México, 1, 2007, pp. 99-107.

"Posibilidades de un comparativismo intralatinoamericano (Rulfo y Graciliano Ramos en la perspectiva de Hermenegildo Bustos)", en Latinoamérica, México, 44, 2007, pp. 9-27.

“Aproximación a la poética de Édouard Glissant", en Rosalba Lendo y Laura López Morales (coords.), Francofonía y diversidad cultural. Rostros de la francofonía, México, FFyLUNAM, 2007.

"En defensa de la tradición letrada", en Norma de los Ríos e Irene Sánchez, América Latina: historia, realidades y desafíos, México, FFyL-UNAM, 2005.

“¿Qué nos dice hoy La ciudad letrada de Ángel Rama?”, en Revista Iberoamericana, Pittsburgh, 71, 2005, pp. 363-372.

"Historia y memoria en Balún Canán de Rosario Castellanos", en Poligrafías, México, 2003, pp. 31-51.

De selvas y selváticos: ficción autobiográfica y poética narrativa en Jorge Issacs y José Eustasio Rivera, Bogotá, Universidad Nacional de Colombia / Universidad de los Andes / Plaza \& Janés, 1998.

“Los silencios de Juan Rulfo”, en Revista Canadiense de Estudios Hispánicos, 21, 1998, pp. 5983.

“A propósito de la propuesta historiográfica de Ángel Rama”, en Mabel Moraña (coord.), Ángel Rama y los Estudios Latinoamericanos, Pittsburgh University, 1997.

“Aproximación a la poética de Lucía Jerez (música y pintura en el proceso de simbolización)”, en Rocío Antúnez y Aralia López (coords.), José Martí, poética y política, México, UAM, 1997.

"Historia y tradición literaria en los Seis ensayos de Pedro Henríquez Ureña", en Jorge Ruedas de la Serna (coord.), Historiografía de la literatura mexicana, México, UNAM, 1996.

El realismo social en perspectiva. México, IIS-UNAM, 1995 [edición revisada con respecto a la $1^{\mathrm{a}}$ de 1982]. El título de la $1^{\mathrm{a}}$ ed. es Historia y crítica literaria. El realismo social y la crisis de la dominación oligárquica.

“El dialogismo y la poética histórica bajtinianos en la perspectiva de la heterogeneidad cultural y la transculturación narrativa en América Latina", en Revista de crítica literaria latinoamericana, 21, 1995, pp. 29-44.

(Comp.) Historia y literatura, México, Instituto Mora, 2001 [1ª ed. 1994].

"La poética narrativa de Agustín Yáñez en Al filo del agua", en Agustín Yánez, Al filo del agua, edición crítica coordinada por Arturo Azuela, ALLCA XX, Colección Archivos, 1992.

"Universalidad del regionalismo: Canaima de Rómulo Gallegos", en Rómulo Gallegos, Canaima, edición crítica coordinada por Charles Minguet, ALLCA XX, Colección Archivos, 1991.

“La sociocrítica frente a Agustín Yáñez”, en Literatura Mexicana, 11, 1991, pp. 336-351.

Literatura y sociedad en América Latina: el modernismo, México, Siglo Veintiuno, 1978 [1ª ed. La Habana, 1976].

\section{Otras referencias}

Angenot, Marc, El discurso social. Los límites históricos de lo pensable y lo decible, Buenos Aires, Siglo Veintiuno, 2012. 
Castoriadis, Cornelius, "Imaginario e imaginación en la encrucijada", en Figuras de lo pensable, Buenos Aires, FCE, 2001.

Cornejo Polar, Antonio, Escribir en el aire. Ensayo sobre la heterogeneidad socio-cultural en las literaturas andinas, Lima, Latinoamericana Editores/CELACP, 2003 [1994].

Cusset, François, French Theory. Foucault, Derrida, Deleuze $\mathcal{E}$ Cia, y las mutaciones de la vida intelectual en Estados Unidos, Barcelona, Melusina, 2005 [ $1^{\text {a }}$ ed. 2003].

Devés, Eduardo y Andrés Kozel, Estudios eidéticos. Una conversación desde el Sur sobre la vida de las ideas y la reconfiguración de un espacio disciplinar, Santiago de Chile, Ariadna, 2018.

Egido, Luciano G., Agonizar en Salamanca: Unamuno, julio-diciembre de 1936, Barcelona, Tusquets, 2006.

García Canclini, Néstor, reseña de Alejandro Losada La literatura en la sociedad de América Latina, en Cahiers du monde hispanique et luso-brésilien, 42, 1984, 184-186.

Hartog, François, Regímenes de historicidad. Presentismo y experiencias del tiempo, México, Universidad Iberoamericana, 2007 [ $1^{\mathrm{a}}$ ed. 2003].

Kozel, Andrés, “El estudio del pensamiento latinoamericano en nuestros días. Notas para una caracterización". En Prismas, revista de historia intelectual, UNQui, 19, 2015, pp. 163-172.

Palti, Elías, El momento romántico. Nación, historia y lenguajes políticos en la Argentina del siglo XIX, Buenos Aires, Eudeba, 2009.

Pulido Herráez, Begoña, reseña del libro de Françoise Perus, Juan Rulfo, el arte de narrar, en Latinoamérica, 56, México, 2013, 284-290.

Rama, Ángel, Transculturación narrativa en América Latina, México, Siglo Veintiuno, 1985 [1 ${ }^{\text {a }}$ ed. 982].

Schorske, Carl E., La Viena de fin de siglo. Política y cultura, Buenos Aires, Siglo Veintiuno, 2011 [ $1^{\mathrm{a}}$ ed. 1980].

Sobrevilla, David, “Transculturación y heterogeneidad: avatares de dos categorías literarias en América Latina", en Revista de crítica literaria latinoamericana, núm. 54, LimaHanover, 2001, pp. 21-33.

Velázquez Soto, Armando, reseña de la antología compilada por Françoise Perus, La historia en la ficción y la ficción en la historia. Reflexiones en torno a la cultura y algunas nociones afines: historia, lenguaje y ficción, en Poligrafías, Nueva Época, 1, México, 2011, 159-164. 